\title{
A NEUROPSYCHOLOGICAL STUDY OF INTERHEMISPHERIC INTEGRATION OF INVOLUNTARY MEMORY PROCESSES
}

\author{
Marija S. Kovyazina, \\ Darya A. Kuznetsova \\ Lomonosov Moscow State University \\ Moscow
}

\begin{abstract}
Split Brain Syndrome as it is described in neuropsychology includes impairments of perceptual and motor activity, more specifically the impairments in coordination of motor responses in bimanual tasks as well as in perception, speech and space impairments. There's little evidence about the specification of memory processes impairments in the corpus callosum (cc) pathology. The conducted experiment demonstrated that cc performs the function of distribution of energy between the brain hemispheres and suppress the subdominant in the present activity, forcing the interhemispherical asymmetry, suppressing the identical process in the subdominant hemisphere. CC also significantly influences the process of selectivity in involuntary memory and learning.
\end{abstract}

Keywords: neuropsychology, impairment, memory, interhemispheric integration

Split Brain Syndrome as it is described in neuropsychology includes impairments of perceptual and motor activity, more specifically the impairments in coordination of motor responses in bimanual tasks as well as in perception, speech and space impairments (Gazzaniga, 2004; Moskovichjute et al., 1982; Homskaja, 2007).

There's little evidence about the specification of memory processes impairments in the corpus callosum (cc) pathology (Simernickaja, 1989; Guise et al., 1999; Mayers \& Sperry, 1985; Zaidel \& Sperry, 1974). On the one hand, it can be explained by the instability of the symptoms (Clark \& Geffen, 1989; Gazzaniga, 2000). Since there are distinct lateral differences in memory impairments we can assume, that there are different aspects of memory activity that are laterilized. And that memory is a complex holistic integrative activities, means that we need a mechanism 
of interaction of left-and right-brain perspective. We can logically assume, that cc pays its' role in integration of memory processes and if it occurs pathology, the hole memory system suffers because of the fact, that $\mathrm{cc}$ connects all cortical sections of left and right hemisphere. On the other hand, studies of the cc pathology are traditionally focused on the measurement of the voluntary level of the mental activity. In this case, several authors noted the similarity of symptoms of cc and right hemisphere pathology (Buklina, 2004; Kovyazina \& Balashova, 2009). So, we can assume that specifically involuntary processes (that laterilized in right hemisphere) are the first to suffer in the patients with the loss of interhemispheric connectivity based on cc abnormalities. Symptoms in this case are more stable because of the lack of compensation. Thus, specifically the involuntary memory system is to be more vulnerable due to cc impairment.

The involuntary memory is an organism's ability to store, retain, and recall information and experiences without conscious effort (Falikman \& Kojfman, 2005). Involuntary memory (compared with voluntary) is automatic process and is characterized by high rate, rigidity, unconsciousness (Gippenrejter \& Romanov, 2000; Falikman \& Kojfman, 2005). It's mostly perceptual and motor skills. Neuroimaging studies demonstrate the involvement in voluntary and involuntary memory fundamentally different structures, which function almost independently (Buckner et al., 1996).

The involuntary level of memory activity includes skills which are the consequence of automatic, repeated, standard unconsciousness actions as well as priming effects.

Learning in psychology is traditionally described as acquiring changes of individual cognitive and behavioral patterns in accordance with previous experience. The learning ability of brain (the ability to develop new skills) is connected with neuroplasticity (the ability of the human brain to change as a result of one's experience). The most studied is the phenomenon of plasticity of primary sensory and motor cortex (Grunwald, 2008). CC which is responsible for integrative activity of brain hemispheres and interhemispheric transfer of information supplies normal functioning of motor sphere and perception brain systems and hence influences sensorimotor learning. Therefore, symptoms of the cc pathology occur primarily in the sensorimotor area (Korsakova \& Moskovichjute, 2007). 
Another subsystem of involuntary memory along with the sensorimotor learning is perceptual subsystem, which traditionally includes priming effects. Priming effect is a change of velocity and accuracy of the reaction after the presentation of information, which is connected with content or context of the task, but not directly correlated to its purpose and requirements. Also priming effects can be observed in the increased probability of spontaneous retrieving this information in suitable conditions (Falikman \& Kojfman, 2005). There are different types of priming (on several grounds):

- Emotional and cognitive.

- Consciousness and unconsciousness.

- Perceptual and semantic (perceptual coding is based on the resemblance of objects, and semantic coding includes semantic categorization of objects).

Studies of interhemispheric transfer of the involuntary memory traces in the situation of unconsciousness priming in normal subjects with intact brain commissures discovered that reaction time (RT) doesn't change between the ipsy- or contralateral performance of prime and target (Reynvoet, Ratinckx, \& Notebaert, 2008). RT decreases when prime and target are relevant and increases if not. Studies of emotional priming discovered that emotionally intense words, presented subconsciously, influence the RT in positive and negative targets. The most rapid responses were observed in case of emotional congruency between primes and targets. Although subjects with high level of anxiety significantly slow down after the performing of subconsciousness emotionally negative priming (Hermans et al., 2003).

The similar studies were conducted within the subjects with acc or childhood collosotomy (Forget, Lippe, \& Lassonde, 2009). These investigations demonstrated the lack of interhemispheric transfer of the subconscious perception information. And ipsylateral priming effects were no different from control subjects.

Thus, there is the impairment of the interhemispheric transfer of the involuntary memory traces in cc pathology. Although there is still vague - which traces cannot be transferred?

The purpose of the study is to identify and study the contribution of interhemispheric interaction in the work of involuntary memory.

The experiment was conducted during the standard clinical neuropsychological examination. The subjects with the pathology of cc dem- 
onstrated tendency to unilateral spatial neglect, spatial errors. In tactile sphere we could observe single anomy errors. There were insignificant difficulties in the performing bimanual reciprocal task in praxis (mostly in left hand) and difficulties in the transfer pose of the fingers without visual control. Also there were some unspecific impairment in voluntary memory in situations with interference.

The experimental group consisted of 11 patients with the cc pathology of various origin (full or partial agenesis of the cc, hypoplasia of the cc, dysgenesia of the $c c$, atrophic processes, tumors or vascular lesions). The oldest participant was 73, the youngest - 9. Control group consisted of 43 normal right-handed subjects. The oldest was 53 , the youngest -17 .

In the experiment we presented to the subjects two photos of quite similar women in left or right visual field.

Subjects had the task of binary classification. If they saw the first woman, they had to push the right button on the keyboard, if they saw the second woman - the left. The target performance was preceded by short subconscious performance $(5 \mathrm{~ms})$ of the same or different photo (relevant or irrelevant prime). There was also series of control trials without priming at all. In the center of the screen there was fixation point.

Every trial went the same way. There was $5 \mathrm{~ms}$ priming (or just dark screen - in trials without priming). After $500 \mathrm{~ms}$ pause (dark screen) there was $1500 \mathrm{~ms}$ performance of the target, to which subject reacted. The trial ended with the $1000 \mathrm{~ms}$ pause.

We composed stimuli in pairs (prime - target), which differed in the following criteria:

1. Presence or absence of priming.

2. Relevancy or irrelevancy of priming.

3. The visual field of primes' and targets' performance:

- prime and target appear in the right visual field;

- prime and target appear in the left visual field;

- prime appears in right, and target appears in left visual field.

- prime appears in left, and target appears in right visual field.

Thus, there were 20 different pairs of stimuli. Each of them was performed to the subject 20 times, Pairs of stimuli were performed randomly. The experiment lasted 21.5 minutes.

We analyzed only correct responses. We've got $400 \mathrm{RT}$ for each subject, which was divided into 10 groups of answers: 
1. No priming, target's on the left.

2. No priming, target's on the right.

3. Relevant prime's on the left, target's on the left.

4. Relevant prime's on the left, target's on the right.

5. Relevant prime's on the right, target's on the right.

6 . Relevant prime's on the right, target's on the left.

7. Irrelevant prime's on the left, target's on the left.

8. Irrelevant prime's on the left, target's on the right.

9. Irrelevant prime's on the right, target's on the right.

10. Irrelevant prime's on the right, target's on the left.

Group resulting values were compared with each other using the nonparametric Mann-Whitney test, during which statistically significant correlations were showed.

\section{Results and discussion}

The results of the control group are following:

1. In case of the absence of priming (conditions 1-2) the RT was significantly shorter in case of target in the left visual field $(\mathrm{U}=538, \mathrm{p}=$ $0,001)$.

2. In all cases of relevant prime and target (conditions 3-6) there was significantly decreased RT compared with cases of the absence of priming and target's on the same visual field $(3: \mathrm{U}=545, \mathrm{p}=0,001 ; 4: \mathrm{U}=569$, $\mathrm{p}=0,002 ; 5: \mathrm{U}=563, \mathrm{p}=0,002 ; 6: \mathrm{U}=630, \mathrm{p}=0,011)$.

3. In all cases of irrelevant prime and target (conditions 7-10) there was significant increasing of the RT compared with cases of the absence of priming and target's on the same visual field $(7: \mathrm{U}=470, \mathrm{p}=0,001$; 8: $U=588, p=0,004 ; 9: U=550,5, p=0,001 ; 10: U=603, p=0,005)$.

So, in control subjects there was a significant correlation between $\mathrm{RT}$ on the target and priming. In case of relevant prime RT decreased. In case of irrelevant prime RT increased.

Patient with the cc pathology (experimental group) demonstrated following performing on the task:

1. In trials without priming (conditions 1-2) this subjects demonstrated no significant differences in the trials with performing target in left and right visual field because of the increased RT of the left hemisphere $(\mathrm{U}=57, \mathrm{p}=0,847)$. In both conditions 1 and $2 \mathrm{RT}$ did not 
significantly differ from the normal RT $(1: \mathrm{U}=185, \mathrm{p}=0,269 ; 2: \mathrm{U}=169$, $\mathrm{p}=0.147$ ). Although there was a tendency in condition 2 (no priming, target's on the right) to decrease RT compared with normal RT, what caused the reduction of hemispheric asymmetry in the RT in cases without priming in the subjects with cc pathology. This fact can be explained by the assumption that in case of the impairment of the interhemispheric interactions right hemisphere ceases to suppress left, and left hemisphere shows increased activity. So, normally cc performs the function of the activity distribution between the hemispheres, which is necessary for the dominant hemisphere to suppress subdominant.

2 . In the trials, in which prime and target (no matter relevant, or irrelevant) performed in the right visual field (conditions 5 and 9) we could observe significant decrease of the RT in compare with the condition 2 (target's on the right, no priming) (5: $U=30, p=0,047 ; 9: U=29$, $p=0,040)$. So, left hemisphere cannot distinguish primes properly, but it distinguishes the formal presence of priming and can detect any priming as the correct. Because of the fact, that left hemisphere is dominant in conscious processes, it can tell (fixate) the presence of priming (that there's some flashing image before the target). Although it can't tell specifically, which one prime was presented, because right hemisphere is dominant in the proceeding of unconsciousness information. Left hemisphere, isolated from right, is able of learning (forming a skill) in the basement of the formal presence of priming: relevant prime is assessed proper and irrelevant prime is underestimated. And also we have to admit, that in condition 9 (irrelevant prime and target, both - on the right) there is decreased RT compared with normal results $(U=52, p=0,001)$. And in condition 5 (relevant prime and target, both are on the right) there were no significant differences from normal results $(U=203$, $\mathrm{p}=0,472)$. So, with right hemisphere reacts properly on the presence of relevant prime by decreasing RT (it begins to be just like normal). Although in case of irrelevant priming left hemisphere reacts the same way: RT decreases to the level of relevant priming. And in control group in all cases, included irrelevant primes and targets, we can observe increased RT compared with no-priming trials. In other words, in case of irrelevant priming much more time is necessary for the operation of comparison of the prime and target and inhibition wrong reaction. And in the cc pathology this thing doesn't occur. 
3. In case of performing primes and targets, no matter relevant or not, in the left visual field (conditions 3 and 7) there were not significant differences from the condition 1 (no priming, target's in the left) (3: $\mathrm{U}=53, \mathrm{p}=0,653 ; 7: \mathrm{U}=49, \mathrm{p}=0,478$ ). We observed increasing of the RT in condition 3 (relevant prime and target) $(\mathrm{U}=109, \mathrm{p}=0,006)$ and decreasing of the RT in condition 7 (irrelevant prime and target) $(\mathrm{U}=126, \mathrm{p}=0,018)$ compared with normal reactions. So, we can say, that there was an increasing of the RT in subjects with cc pathology in cases, in which there was a decreasing of the RT in normal subjects. And that there was a decreasing of the RT in subjects with cc pathology in cases, in which there was an increasing of the RT in normal subjects. So, RT of the right hemisphere, isolated from left, wasn't different from the RT in case of no-priming in subjects with cc pathology and in normal subjects. Right hemisphere ignores the presence of priming! The RT doesn't show any learning. But such ignorance of the priming presence itself can be connected with the fact that in the normal interhemispheric interaction left hemisphere is dominant for the memory traces fixation (which is confirmed by the left hemisphere RT, which fixated priming presence, but didn't conduct its' content processing). Right hemisphere in case of cc pathology can't fixate the memory traces on its' own, that's why it acts just like there isn't any traces at all. In other words, we can talk about tendency to left unilateral neglect on the involuntary level of memory activity that is caused by interhemispheric interactions impairment.

4. In all trials, when prime and target, no matter relevant or not, were performed in contralateral visual fields (conditions $4,6,8,10$ ), we observed RT, increasing compared with the conditions 1 and 2 (no priming) (4: $U=30, p=0,047 ; 6: U=26, p=0,023 ; 8: U=28, p=0,040$; 10: $\mathrm{U}=23, \mathrm{p}=0,013)$. We also can observe RT increasing in conditions 4, 6, $8(4: \mathrm{U}=107, \mathrm{p}=0,005 ; 6: \mathrm{U}=45, \mathrm{p}=0,001 ; 8: \mathrm{U}=322, \mathrm{p}=0,036)$ and no significant differences in condition $10(\mathrm{U}=222, \mathrm{p}=0,755)$ in compare with control subjects' reactions. In all this conditions the influence of interhemispherical interactions on reaction increases and we can analyze the variability of this impact compared with normal subjects. The difference depends not only on the slowdown of the RT (compared with normal subjects and conditions 1 and 2), but also with the fact that both hemispheres don't react on any priming properly. In fact, hemi- 
spheres don't "see" relevant priming. On the one hand, brain notices the differences (and that matches the conditions 5 and 9), on the other hand, these differences don't automate, don't lead to learning (and that matches conditions 3 and 7). Irrelevant primes are estimated right and relevant are overestimated. This situation can be seen as compensatory with the participation of both hemispheres in the process of reaction. Right hemisphere can't ignore the presence of priming, as it appears in case of hemispheres isolated functioning, because left hemisphere fixates the presence. And left hemisphere can't ignore the content processing of right hemisphere, that interfere with building formal skills (like reacting just to the presence of priming). But in subjects with cc pathology transfer of information about presence and content of the stimuli occurs through compensatory paths: subcortical structures and anterior commissure that significantly slows down the work of involuntary memory and in case of rapid activity doesn't let form the skill. In every case prime processes as irrelevant that leads to decreasing the probability of error reaction. Thus, compensation goes the way of rejection the automatic, rapid, rigid unconscious processes in favor of a more energy-intensive ways of reaction.

Thus, the conducted experiment demonstrated that cc performs the function of distribution of energy between the brain hemispheres and suppress the subdominant in the present activity, forcing the interhemispherical asymmetry, suppressing the identical process in the subdominant hemisphere. CC also significantly influences the process of selectivity in involuntary memory and learning.

In addition, to clarify the results it is necessary to match the experimental data, with data obtained in groups of subjects with unilateral local brain lesions - patients with pathology of the right and left hemispheres.

\section{References}

Buckner, R.L., Raichle, M.E., Miezin, F.M., \& Petersen, S.E. (1996). Functional anatomic studies of memory retrieval for auditory words and visual pictures. The Journal of Neuroscience, 16(19), 19-35.

Buklina, S.B. (2004). Mozolistoe telo, mezhpolusharnoe vzaimodejstvie i funkcii pravogo polusharija mozga [Corpus callosum, interhemispheric interaction and function of the right hemisphere of the brain]. Zhurn. nevrologii i psikhiatrii, 5, 8-14. 
Clark, C.R., \& Geffen, G.M. (1989). Corpus Callosum surgery and recent memory. Brain, 112(1), 165-175.

Falikman, M.V., \& Kojfman, A.Ja. (2005). Vidy prajminga v issledovanijah vosprijatija i perceptivnogo vnimanija [Types of priming in studies of perception and perceptual attention]. Vestnik Mosk. Un-ta. Serija 14, Psikhologija, 3, 86-97; 4, 81-89.

Forget, J., Lippe, S., \& Lassonde, M. (2009). Perceptual priming does not transfer interhemispherically in acallosal brain. Experimental Brain Research, 192(3), 443-454.

Gazzaniga, M.S. (2000). Cerebral specialization and interhemispheric communication. Does the corpus callosum enable the human condition? Brain, 123, 93-126.

Gazzaniga, M. (2004). Rasscheplennyj chelovecheskij mozg [Split the human brain]. In E.D. Homskaja (Ed.), Hrestomatija po nejropsihologii [Chrestomathy on neuropsychology] (pp. 212-218). Moscow: Institut obschegumanitarnyh issledovanij; Moskovskij psikhologo-social'nyj institut.

Gippenrejter, Ju.B., \& Romanov, V.Ja. (Eds.). (2000). Psikhologija pamjati [Psychology of memory]. Moscow: CheRo.

Grunwald, M. (Ed.). (2008). Human Haptic Perception: Basics and Applications. Basel: A Birkhäuser Basel book.

Guise, E., Pesce, M., Foschi, N., Quattrini, A., Papo, I., \& Lassonde, M. (1999). Callosal and cortical contribution to procedural learning. Brain, 122, 49-62.

Hermans, D., Spruyt, A., De Houwer, J., Eelen, P. (2003). Affective priming with subliminally presented pictures. Canadian Journal of Experimental Psychology, 57(2), 97-114.

Homskaja, E.D. (2007). Nejropsikhologija [Neuropsychology]. St.-Petersburg: Piter.

Korsakova, N.K., \& Moskovichjute, L.I. (2007). Klinicheskaja nejropsikhologija [Clinical neuropsychology]. Moscow: IC Akademija.

Kovyazina, M.S., \& Balashova, E.Ju. (2009). Osobennosti vysshih psikhicheskih funkcij pri patologii mozolistogo tela [Features of higher mental functions in the pathology of the corpus callosum]. Vestnik Tomskogo Gosudarstvennogo Universiteta, 113, 193-200.

Mayers, J.J., \& Sperry, R.W. (1985). Interhemispheric communication after section of the forebrain commissures. Cortex, 21, 249-260.

Moskovichjute, L.I., Simernickaja, Je.G., Smirnov N.A., \& Filatov Ju.F. (1982). O roli mozolistogo tela $\mathrm{v}$ organizacii vysshih psikhicheskih funkcij [On the role of the corpus callosum in the organization of higher mental functions]. In E.D. Homskaja, L.S. Cvetkova, \& B.V. Zejgarnik (Eds.), A.R. Lurija i sovremennaja psikhologija (Sbornik statej pamjati A.R. Lurii) [A.R. Lurija and contemporary psychology. Collection of articles devoted to the memory of A.R.Luria] (pp. 143-150). Moscow: Izd-vo Mosk. un-ta. 
Reynvoet, B., Ratinckx, E., \& Notebaert, K. (2008). Intra- and interhemispheric number priming: evidence for rapid integration of magnitude information between hemispheres. Cortex, 44(6), 728-736.

Simernickaja, Je.G. (1989). Nejropsikhologicheskaja diagnostika narushenij pamjati pri porazhenijah mozolistogo tela [Neuropsychological diagnosis of memory disorders in patients with lesions of the corpus callosum]. In E.D. Homskaja i dr. (Eds.), Novye metody nejropsikhologicheskogo issledovanija [New methods of neuropsychological research] (pp. 159-175). Moscow: Izd-vo Instituta psikhologii AN SSSR.

Zaidel, D.W., \& Sperry, R.W. (1974). Memory impairment after commissurotomy in man. Brain, 97, 263-272. 